\title{
Assessment of Lead and Cadmium Levels in Frequently Used Cosmetic Products in Iran
}

\author{
H. Nourmoradi, ${ }^{1}$ M. Foroghi, ${ }^{2}$ M. Farhadkhani, ${ }^{3}$ and M. Vahid Dastjerdi ${ }^{3}$ \\ ${ }^{1}$ Department of Environmental Health Engineering, School of Health, Ilam University of Medical Sciences, Ilam, Iran \\ ${ }^{2}$ Department of Environmental Health Engineering, School of Health, Hamadan University of Medical Sciences, Hamadan, Iran \\ ${ }^{3}$ Department of Environmental Health Engineering, Environment Research Center, School of Health, \\ Isfahan University of Medical Sciences, Hezar Jerib Avenue, Isfahan, Iran
}

Correspondence should be addressed to M. Vahid Dastjerdi; vahid@hlth.mui.ac.ir

Received 27 July 2013; Revised 17 August 2013; Accepted 19 August 2013

Academic Editor: David O. Carpenter

Copyright (c) 2013 H. Nourmoradi et al. This is an open access article distributed under the Creative Commons Attribution License, which permits unrestricted use, distribution, and reproduction in any medium, provided the original work is properly cited.

\begin{abstract}
This study aims to investigate the content of lead and cadmium in most frequently used brands of cosmetic products (lipstick and eye shadow) in Iran. Fifty samples of lipstick ( 5 colors in 7 brands) and eye shadow ( 3 colors in 5 brands) were selected taken from large cosmetic stores in Isfahan (Iran) and lead and cadmium of them were analyzed. The results showed that the concentration of lead and cadmium in the lipsticks was within the range of $0.08-5.2 \mu \mathrm{g} / \mathrm{g}$ and $4.08-60.20 \mu \mathrm{g} / \mathrm{g}$, respectively. The eye shadow samples had a lead level of $0.85-6.90 \mu \mathrm{g} / \mathrm{g}$ and a cadmium level of $1.54-55.59 \mu \mathrm{g} / \mathrm{g}$. The content range of the heavy metals in the eye shadows was higher than that of the lipsticks. There was significant difference between the average of the lead content in the different brands of the lipsticks and eye shadows. Thus, the continuous use of these cosmetics can increase the absorption of heavy metals, especially $\mathrm{Cd}$ and $\mathrm{Pb}$, in the body when swallowing lipsticks or through dermal cosmetic absorption. The effects of heavy metals such as lead can be harmful, especially for pregnant women and children. Therefore, effort must be made to inform the users and the general public about the harmful consequences of cosmetics.
\end{abstract}

\section{Introduction}

Many thousands of years ago, the people of primary societies used various materials in order to beautify their faces [1]. Eye shadow and lipstick are a group of cosmetic products that have been most commonly used in various parts of the world. Many studies have reported that cosmetic products contain relatively high concentrations of heavy metals [2-7]. Kohl, a type of customary cosmetic product used for eyeliner in the Middle East, contains more than $50 \%$ of lead [5]. On the basis of a study, it was determined that the concentration of blood lead in a seven-month baby was $39 \mu \mathrm{g} / \mathrm{dL}$ because of the consumption of kohl [8]. The use of leaded eye cosmetics has been observed to be strongly correlated with elevated blood lead levels [9]. Lipstick and eye shadow have various components including antioxidants, pigments, waxes, oils, and inorganics such as silica, $\mathrm{TiO}_{2}$, copper powder, and aluminum powder, bronze powder. Heavy metals are found in ingredients that naturally contain heavy metals or are polluted with them during production or by containers $[7,10]$.
Some toxic elements including heavy metals (lead, cadmium, etc.) have been found as impurities in pigments of lipsticks, eye shadows, and face powders $[4,6]$. Al-Saleh et al. showed that heavy metals (e.g., lead) can be absorbed by children's and women's skin through using cosmetic products $[2,3]$.

Contact with low concentration of lead can cause disorders such as behavioral abnormalities and decreased learning and hearing and can result in adverse effects on central nervous system, reproductive system, hematopoiesis, anemia, and hepatic and renal systems [1,11-13]. More than $90 \%$ of lead absorbed by human is concentrated in the bones with a half-life of greater than 20 years [14]. Cadmium is one of the major heavy metals found in some natural colors and inorganic pigments of cosmetic products [10]. Cadmium can concentrate primarily in kidney, bones, and teeth, and long-term contact with it causes growth retardation of rat fetus and teratogenic consequences and weight loss $[1,15]$. The half-life of cadmium in human is determined to be 1035 years [15]. International Agency for Research on Cancer (IARC) has categorized lead and cadmium in group 2A of 
TABLE 1: Concentration of lead and cadmium in different brands of cosmetic products.

\begin{tabular}{|c|c|c|c|c|c|c|c|c|}
\hline \multirow{2}{*}{ Brand } & \multicolumn{4}{|c|}{ Lead content ( $\mu \mathrm{g} / \mathrm{g}$ of wet weight) } & \multicolumn{4}{|c|}{ Cadmium content ( $\mu \mathrm{g} / \mathrm{g}$ of wet weight) } \\
\hline & Min & Max & St. dev. & Average & Min & Max & St. dev. & Average \\
\hline \multicolumn{9}{|c|}{ Lipstick } \\
\hline 1 & 0.48 & 3.00 & 0.96 & 2.03 & 5.84 & 17.97 & 5.06 & 14.82 \\
\hline 2 & 0.08 & 2.40 & 0.92 & 0.93 & 7.12 & 40.52 & 13.69 & 16.41 \\
\hline 3 & 0.36 & 0.93 & 0.26 & 0.58 & 12.49 & 32.68 & 8.99 & 19.75 \\
\hline 4 & 0.05 & 4.20 & 1.67 & 1.47 & 4.08 & 59.96 & 26.42 & 26.66 \\
\hline 5 & 0.26 & 3.12 & 1.12 & 1.18 & 5.60 & 38.08 & 12.62 & 17.29 \\
\hline 6 & 0.08 & 1.49 & 0.65 & 0.97 & 11.33 & 14.68 & 1.33 & 12.99 \\
\hline 7 & 1.80 & 5.20 & 1.59 & 3.36 & 28.46 & 60.20 & 12.92 & 37.96 \\
\hline \multicolumn{9}{|c|}{ Eye shadow } \\
\hline 1 & 4.47 & 6.90 & 1.22 & 1.55 & 20.72 & 50.62 & 15.30 & 33.72 \\
\hline 2 & 2.27 & 2.70 & 0.22 & 2.50 & 17.62 & 55.59 & 21.75 & 30.47 \\
\hline 3 & 3.74 & 6.00 & 1.15 & 5.00 & 1.54 & 39.18 & 19.13 & 22.35 \\
\hline 4 & 0.85 & 1.63 & 0.42 & 1.15 & 6.42 & 41.32 & 19.44 & 28.82 \\
\hline 5 & 2.57 & 4.57 & 1.07 & 3.35 & 16.75 & 24.01 & 3.90 & 21.23 \\
\hline
\end{tabular}

carcinogen [15]. It is well proven that lead and cadmium can pass the placenta for the period of pregnancy and have been related to uterus fetal death before the proper time of delivery and low birth weight $[16,17]$. US Food and Drug Administration (FDA) has shown that the average concentration of lead in 400 samples of lipsticks was $1.11 \mu \mathrm{g} / \mathrm{g}$ [7]. In 2007, a study on the lead concentration of 33 brands of lipsticks showed that $61 \%$ of tested lipsticks have measurable lead $(0.03-0.65 \mu \mathrm{g} / \mathrm{g})$ [18]. The US FDA has not set a value as an acceptable level for lead and cadmium in cosmetic products including lipstick. But many studies have used the FDA lead limit for candy $(0.1 \mu \mathrm{g} / \mathrm{g})$ as a permissible standard for lipsticks [19]. It has been determined that women unintentionally swallow 4 pounds of lipstick during their life [20]. Iran among the Middle East countries is the third biggest user of cosmetic products [21]. With regard to this issue and adverse effects of consuming cosmetic products in Iran, the aim of this study was to investigate the concentration of lead and cadmium in the most commonly used brands of cosmetic products (lipstick and eye shadow).

\section{Materials and Methods}

2.1. Samples. Cosmetic products including the most commonly used brands of lipstick (35 samples: 5 colors in 7 brands) and eye shadow (15 samples: 3 colors in 5 brands) were purchased from large cosmetic stores in Isfahan, Iran. The colors studied for each brand of lipstick were orange, black grown, pink, violet, and copper and for each brand of eye shadow were blue, green, and copper.

2.2. Samples Preparation and Analysis. One gram of each sample was placed into a $100 \mathrm{~mL}$ Pyrex glass beaker and digested with $5 \mathrm{~mL}$ of concentrated nitric acid (Merck, 99.99\%) on a hot plate at $80^{\circ} \mathrm{C}$ until it dried. The digestion process was repeated twice. Then, $1 \mathrm{~mL}$ of concentrated $\mathrm{H}_{2} \mathrm{O}_{2}$ was added in order to oxidize completely the organic matter of residues. The residual material was diluted with deionized water to the final volume of $50 \mathrm{~mL}$. The solution was then filtered by Whatman filter (Merck, $0.45 \mu \mathrm{m}$ ) [9]. The concentration of the metal ions in the solution was determined by a Graphite furnace atomic absorption spectrometry (GFAAS, Model AAnalyst 300). The detection limit of the GFAAS was $0.1 \mathrm{ppb}$ for both metals. The metal ion content in the cosmetic products was reported as microgram per gram $(\mu \mathrm{g} / \mathrm{g})$ on the basis of wet weight. Statistical analysis (SPSS-16, one-way ANOVA) was conducted to determine the relation of metal ion concentration among the cosmetic products. The $P$ value of 0.05 was considered as significant.

\section{Results and Discussion}

Fifty samples of lipstick (35 samples) and eye shadow (15 samples) were investigated in this study. The samples analyzed showed that lead and cadmium were detected in all brands of the cosmetics with varying concentrations (Table 1). As seen, the concentration of lead and cadmium in the lipsticks was within the range of $0.08-5.2 \mu \mathrm{g} / \mathrm{g}$ and $4.08-60.20 \mu \mathrm{g} / \mathrm{g}$, respectively. The eye shadow samples had also a lead level of $0.85-6.90 \mu \mathrm{g} / \mathrm{g}$ and a cadmium level of $1.54-55.59 \mu \mathrm{g} / \mathrm{g}$.

Based on the results illustrated in Table 1 , cadmium content in both cosmetic products was higher than lead content $(P<0.04)$. There was a significant difference between the average of the lead content in the different brands of the lipsticks $(P=0.018)$. Similar results were obtained for the different brands of eye shadows $(P=0.02)$. The statistical analysis also confirmed the meaningful difference between cadmium content for various brands of lipstick $(P<0.03)$, but this result did not attain for the eye shadows $(P>0.05)$. Because of the lack of governmental and international rules associated with the maximum permissible content of lead in cosmetics, the Campaign for Safe Cosmetics (CSC) has set 
$0.1 \mu \mathrm{g} / \mathrm{g}$ for lead in cosmetics such as lipstick. This rule has been assigned on the basis of the maximum allowable lead concentration in candy, because it has been assumed that lipstick may be directly taken in via the mouth [18]. This standard value is much lower than that of the lead level in most lipsticks in various studies [9, 22-24]. Therefore, it is seen that this is not a valid standard because candy is used for ingestion, but lipstick is externally consumed on the lips and it may be inadvertently ingested [25].

US Food and Drug Administration (USFDA) has suggested that the concentration of some heavy metals such as nickel, cobalt, and chromium in color additive cosmetics should be less than $170 \mu \mathrm{g} / \mathrm{g}$ and that of lead should be less than $20 \mu \mathrm{g} / \mathrm{g}[25,26]$. As shown in Table 2, the content of lead in the studied cosmetic products was much lower than $20 \mu \mathrm{g} / \mathrm{g}$, which meets the US FDA regulation.

In comparison with other sources such as water, air, and food, daily exposure to heavy metals from cosmetics has been considered as a negligible source for human. Nevertheless, because of the cumulative properties of heavy metals in the body during life time, cosmetics can be regarded as a substantial source of the metals $[9,27]$. Even under the best producing methods in the factories, the existence of heavy metals in cosmetics is inevitable [25]. Therefore, in order to diminish the adverse health effects of heavy metals, cosmetics producers must use such ingredients as color additives in their cosmetics to meet FDA's requirements.

The use of leaded cosmetics such as lipstick and eye shadow has been found to severely affect human beings, especially pregnant women, young children, and fetus. In pregnant women lead can easily cross the placenta and produce congenital lead poisoning $[9,28]$. Many studies have proven the relation between consuming leaded cosmetics (lipstick and eye shadow) and elevated blood lead levels $[23,29]$. It has been observed that the blood lead level of eye cosmetics consumers in Pakistan, India, and Saudi Arabia in comparison with nonconsumers was threefold [9]. Blood lead levels under $10 \mu \mathrm{g} / \mathrm{dL}$ may damage neurobehavioral development in children. It has been proved that by increasing one microgram lead per deciliter $(\mu \mathrm{g} \mathrm{Pb} / \mathrm{dL})$ of blood, the intelligence quotient (IQ) of children is reduced by 0.25 points [30]. Lead has also been related to infertility and miscarriage [23]. The continuous use of cosmetics could have adverse effects on the ocular system [9]. These harmful effects can be caused by skin contact [31].

The studies conducted by Nnorom et al., Khalid et al., and Tsankov et al. showed that the values of lead in all tested brands of lipsticks were up to $41.1 \mu \mathrm{g} / \mathrm{g}, 87-123 \mu \mathrm{g} / \mathrm{g}$, and $0.286-6.234 \mu \mathrm{g} / \mathrm{g}$, respectively $[9,22,24]$. The results of the present study showed that the lead content in the lipstick samples was generally lower than that of the mentioned studies. In this study, the content of lead in the eye shadows was also lower than $10 \mu \mathrm{g} / \mathrm{g}$. Al-Saleh et al. showed that the lead levels in 15 different colors of 8 brands of eye shadows were in the range of $0.42-58.7 \mu \mathrm{g} / \mathrm{g}$ [23]. Sainio et al. also reported that the lead content in 25 brands of eye shadows was up to $16.8 \mu \mathrm{g} / \mathrm{g}$ [6]. The concentration of lead in the eye shadows in the present study was also lower than the abovementioned studies.
TABLE 2: Concentration range of lead $(\mu \mathrm{g} / \mathrm{g})$ in the cosmetic products.

\begin{tabular}{lcc}
\hline $\begin{array}{l}\text { Concentration } \\
\text { range }(\mu \mathrm{g} / \mathrm{g})\end{array}$ & \multicolumn{2}{c}{ Frequency percent $(\%)$} \\
\hline$<1$ & Lipstick & Eye shadow \\
$1-2$ & 47.0 & 13.3 \\
$2-5$ & 20.6 & 6.7 \\
$5-10$ & 17.7 & 53.3 \\
\hline
\end{tabular}

TABLE 3: Concentration range of cadmium $(\mu \mathrm{g} / \mathrm{g})$ in the cosmetic products.

\begin{tabular}{|c|c|c|}
\hline \multirow{2}{*}{$\begin{array}{l}\text { Concentration } \\
\text { range }(\mu \mathrm{g} / \mathrm{g})\end{array}$} & \multicolumn{2}{|c|}{ Frequency percent (\%) } \\
\hline & Lipstick & Eye shadow \\
\hline$<10$ & 14.7 & 13.3 \\
\hline $10-20$ & 55.9 & 20.0 \\
\hline $20-30$ & 2.9 & 33.3 \\
\hline $30-40$ & 14.8 & 13.3 \\
\hline $40-50$ & 5.9 & 6.8 \\
\hline$>50$ & 5.8 & 13.3 \\
\hline
\end{tabular}

Tables 2 and 3 also illustrate that the content range of the heavy metals in the eye shadows was higher than that of the lipsticks $(P<0.001$ for lead and $P=0.04$ for cadmium). Table 3 also presents the concentration range of the cadmium in the cosmetic products. As shown, $29.4 \%$ and $66.7 \%$ of the lipstick and eye shadow samples had cadmium content more than $20 \mu \mathrm{g} / \mathrm{g}$, respectively.

The presence of cadmium in the samples can also have harmful effects on the human body. Small amounts of cadmium may result in heart disease, hypertension, kidney and liver damage, and weakened immune system [32].

Health Canada has recommended that the maximum cadmium concentration is $3 \mu \mathrm{g} / \mathrm{g}$ in cosmetics. Therefore, a trace amount of cadmium is not safe [33]. The results of this study (Table 3) showed that the amount of cadmium in the cosmetics under study was much higher than the standard.

Nnorom et al. reported that the average of cadmium levels in several facial cosmetics (eye cosmetics, lipsticks, and lip gloss) was approximately $1 \mu \mathrm{g} / \mathrm{g}$ [9]. Khalid et al. also showed that cadmium content in all brands and colors of lipsticks was within the range of $0.200-0.500 \mu \mathrm{g} / \mathrm{g}$ [22]. The amount of cadmium in the present study in comparison with that of the above study was far more.

Table 4 shows the heavy metals content in various colors of the cosmetic products. As seen, although the lipsticks with copper color have maximum levels of lead $(2.21 \mu \mathrm{g} / \mathrm{g})$ and cadmium $(27.20 \mu \mathrm{g} / \mathrm{g})$, the statistical analysis did not confirm these differences $(P>0.2)$.

The findings (Table 4) also confirmed that eye shadows with golden color have a higher concentration of cadmium $(P=0.043)$, but there was no significant difference between lead content of golden color eye shadow of the other various colors $(P=0.92)$, while Al-Saleh et al. reported that eye shadows with darker color pigments in their formulation 
TABLE 4: Concentration of lead and cadmium in different colors of cosmetic products.

\begin{tabular}{|c|c|c|c|c|c|c|c|c|}
\hline \multirow{2}{*}{ Color } & \multicolumn{4}{|c|}{ Lead content ( $\mu \mathrm{g} / \mathrm{g}$ of wet weight) } & \multicolumn{4}{|c|}{ Cadmium content ( $\mu \mathrm{g} / \mathrm{g}$ of wet weight) } \\
\hline & Min & $\operatorname{Max}$ & St. dev. & Average & Min & $\operatorname{Max}$ & St. dev. & Average \\
\hline \multicolumn{9}{|l|}{ Lipstick } \\
\hline Black brown & 0.10 & 5.20 & 1.87 & 1.55 & 1.52 & 60.20 & 19.16 & 18.21 \\
\hline Copper & 0.48 & 4.97 & 1.74 & 2.21 & 5.84 & 43.36 & 16.26 & 27.20 \\
\hline Orange & 0.10 & 2.68 & 1.11 & 1.07 & 10.76 & 59.90 & 17.57 & 25.54 \\
\hline Pink & 0.32 & 3.20 & 0.75 & 1.37 & 4.08 & 31.90 & 10.43 & 13.30 \\
\hline Violet & 0.23 & 3.12 & 1.04 & 1.49 & 12.42 & 28.46 & 5.45 & 17.26 \\
\hline \multicolumn{9}{|l|}{ Eye shadow } \\
\hline Blue & 0.97 & 6.00 & 1.98 & 3.25 & 16.75 & 55.59 & 14.67 & 33.44 \\
\hline Green & 1.63 & 6.90 & 2.01 & 3.57 & 1.54 & 22.92 & 9.42 & 13.96 \\
\hline Golden & 0.85 & 5.60 & 2.02 & 3.76 & 17.62 & 50.62 & 13.45 & 34.55 \\
\hline
\end{tabular}

have the highest values of heavy metals [23]. Khalid et al. also indicated that the highest concentration of heavy metals was in lipsticks with dark brown and shocking pink colors, and cosmetics with pink color had the lowest metal contents [22].

\section{Conclusion}

The concentration of lead in the cosmetics under study was lower than that of FDA standards, and the cadmium content in the samples was relatively high. The continuous use of these cosmetics can increase the absorption of heavy metals especially $\mathrm{Cd}$ and $\mathrm{Pb}$ into the body when swallowing lipsticks or through dermal cosmetic absorption. The effects of heavy metals such as lead in cosmetics can be harmful. Therefore, effort must be made to inform the users and the general public especially pregnant women and children of the harmful consequences of cosmetics.

\section{Acknowledgments}

This study was supported by the Vice Chancellery for Research of Isfahan University of Medical Sciences, Iran (Grant no. 290085). The authors are grateful to Engineer Haydari Bani for the cooperation in conducting the experiments.

\section{References}

[1] H. Faghihian, H. Nourmoradi, and M. Shokouhi, "Performance of silica aerogels modified with amino functional groups in $\mathrm{PB}(\mathrm{II})$ and CD(II) removal from aqueous solutions," Polish Journal of Chemical Technology, vol. 14, no. 1, pp. 50-56, 2012.

[2] I. Al-Saleh, M. Nester, E. Devol, N. Shinwari, and S. Al-Shahria, "Determinants of blood lead levels in Saudi Arabian schoolgirls," International Journal of Occupational and Environmental Health, vol. 5, no. 2, pp. 107-114, 1999.

[3] I. A. AI-Saleh and L. Coate, "Lead exposure in Saudi Arabia from the use of traditional cosmetics and medical remedies," Environmental Geochemistry and Health, vol. 17, no. 1, pp. 2931, 1995 .

[4] J. Godt, F. Scheidig, C. Grosse-Siestrup et al., "The toxicity of cadmium and resulting hazards for human health," Journal of
Occupational Medicine and Toxicology, vol. 1, no. 1, article 22, 2006.

[5] N. M. Hepp, W. R. Mindak, and J. Cheng, "Determination of total lead in lipstick: development and validation of a microwave-assisted digestion, inductively coupled plasma-mass spectrometric method," Journal of Cosmetic Science, vol. 60, no. 4, pp. 405-414, 2009.

[6] E.-L. Sainio, R. Jolanki, E. Hakala, and L. Kanerva, "Metals and arsenic in eye shadows," Contact Dermatitis, vol. 42, no. 1, pp. $5-10,2000$.

[7] S. Gunduz and S. Akman, "Investigation of lead contents in lipsticks by solid sampling high resolution continuum source electrothermal atomic absorption spectrometry," Regulatory Toxicology and Pharmacology, vol. 65, no. 1, pp. 34-37, 2012.

[8] D. Farley and F. C. Alert, Dangers of Lead Still Linger, FDA Consumer, 1998, http://www.ncbi.nlm.nih.gov/pubmed/9508545.

[9] I. C. Nnorom, J. C. Igwe, and C. G. Oji-Nnorom, “Trace metal contents of facial (make-up) cosmetics commonly used in Nigeria," African Journal of Biotechnology, vol. 4, no. 10, pp. 11331138, 2005.

[10] USFDA, "Summary of color additives listed for use in the United States in food, drugs, cosmetics, and medical devices," Color additives approved for use in cosmetics part 73, subpart C: Color additives exempt from batch certification, United States Food and Drug Administration, 2007, http://www.fda .gov/ForIndustry/ColorAdditives/ColorAdditiveInventories/ ucm115641.htm.

[11] P. A. Meyer, M. J. Brown, and H. Falk, "Global approach to reducing lead exposure and poisoning," Mutation Research, vol. 659 , no. 1-2, pp. 166-175, 2008.

[12] M. A. Gondal, M. M. Nasr, M. M. Ahmed, Z. H. Yamani, and M. S. Alsalhi, "Detection of lead in paint samples synthesized locally using-laser-induced breakdown spectroscopy," Journal of Environmental Science and Health A, vol. 46, no. 1, pp. 4249, 2011.

[13] M. G. Volpe, M. Nazzaro, R. Coppola, F. Rapuano, and R. P. Aquino, "Determination and assessments of selected heavy metals in eye shadow cosmetics from China, Italy, and USA," Microchemical Journal, vol. 101, pp. 65-69, 2012.

[14] WHO, Environmental Health Criteria 165: Inorganic Lead, International Programme on Chemical Safety. World Health Organization, Geneva, Switzerland, 1995. 
[15] WHO, Guidelines for Drinking Water Quality, vol. 1, Recommendations, World Health Organization, Geneva, Switzerland, 2004.

[16] N. C. Papanikolaou, E. G. Hatzidaki, S. Belivanis, G. N. Tzanakakis, and A. M. Tsatsakis, "Lead toxicity update. A brief review," Medical Science Monitor, vol. 11, no. 10, pp. RA329-RA336, 2005.

[17] Ş. Deveci and E. Deveci, "Histopathological changes in incisive teeth of the newborn pups of cadmium-applied female rats during pregnancy," International Journal of Morphology, vol. 28, no. 4, pp. 1131-1134, 2010.

[18] CSC, "A poison kiss: the problem of lead in lipsticks," 2007, http://safecosmetics.org/downloads/A\%20Poison\%20Kiss_report.pdf.

[19] USFDA, "Lead in candy likely to be consumed frequently by small children: recommended maximum level and enforcement policy," US Department of Health and Human Services. Food and Drug Administration, 2006, http://www.fda.gov/Food/GuidanceRegulation/GuidanceDocumentsRegulatoryInformation/ChemicalContaminantsMetalsNaturalToxinsPesticides/ ucm077904.htm.

[20] S. R. Charitra, Poisonous Cosmetics, the Problem of Lead in Lipstick in Nepal, viii+7. Kathmandu: CEPHED, 2012, http:// www.no-burn.org/downloads/CEPHED\%202012\%20Lead\% 20in\%20Lipstick-\%20final\%20print.pdf.

[21] J. Heath, The Veil: Women Writers on Its History, Lore, and Politics, University of California Press, 2008.

[22] A. Khalid, I. H. Bukhari, M. Riaz et al., "Determination of lead, cadmium, chromium, and nickel in different brands of lipsticks," International Journal of Biology, Pharmacy and Allied Sciences, vol. 1, no. 2, pp. 263-271, 2013.

[23] I. Al-Saleh, S. Al-Enazi, and N. Shinwari, "Assessment of lead in cosmetic products," Regulatory Toxicology and Pharmacology, vol. 54, no. 2, pp. 105-113, 2009.

[24] I. Tsankov, I. Iordanova, D. Lolova, S. Uzunova, and S. Dinoeva, "Hygienic evaluation of the content of heavy metals (lead and copper) in cosmetic products," Problemi na Khigienata, vol. 7, pp. 127-136, 1982.

[25] USFDA, CFSAN, Office of Cosmetics and Colors, Lipstick and Lead: Questions and Answers, http://www.fda.gov/Cosmetics/ ProductandIngredientSafety/ProductInformation/ucm137224 .htm.

[26] D. A. Basketter, G. Angelini, A. Ingber, P. S. Kern, and T. Menné, "Nickel, chromium and cobalt in consumer products: revisiting safe levels in the new millennium," Contact Dermatitis, vol. 49, no. 1, pp. 1-7, 2003.

[27] M. I. Castro-González and M. Méndez-Armenta, "Heavy metals: implications associated to fish consumption," Environmental Toxicology and Pharmacology, vol. 26, no. 3, pp. 263-271, 2008.

[28] M. Shannon, "Severe lead poisoning in pregnancy," Ambulatory Pediatrics, vol. 3, no. 1, pp. 37-39, 2003.

[29] J. Omolaoye, A. Uzairu, and C. Gimba, "Heavy metal assessment of some eye shadow products imported into Nigeria from China," Archives of Applied Science Research, vol. 2, no. 5, pp. 76-84, 2010.

[30] C.-L. Wang, H.-Y. Chuang, C.-K. Ho et al., "Relationship between blood lead concentrations and learning achievement among primary school children in Taiwan," Environmental Research, vol. 89, no. 1, pp. 12-18, 2002.

[31] T. P. Moyer, D. N. Nixon, and K. O. Ash, "Filter paper lead testing," Clinical Chemistry, vol. 45, no. 12, pp. 2055-2056, 1999.
[32] A. Chauhan, R. Bhadauria, A. Singh, S. Lodhi, D. Chaturvedi, and V. Tomar, "Determination of lead and cadmium in cosmetic products," Journal of Chemistry and Pharmaceutical Research, vol. 6, pp. 92-97, 2010.

[33] Health Canada, Heavy Metal Hazard-Environmental Defence: the Health Risks of Hidden Heavy Metals in Face Makeup, 2011, http://environmentaldefence.ca/sites/default/files/report_files/ HeavyMetalHazard\%20FINAL.pdf. 


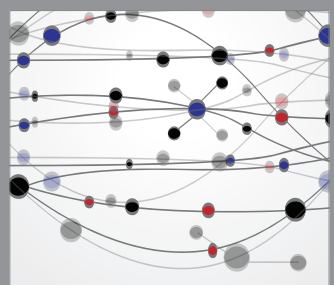

The Scientific World Journal
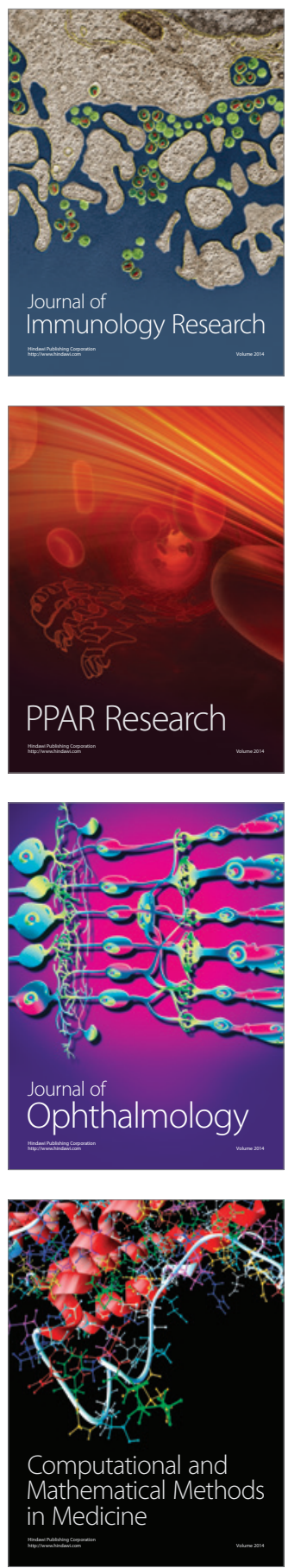

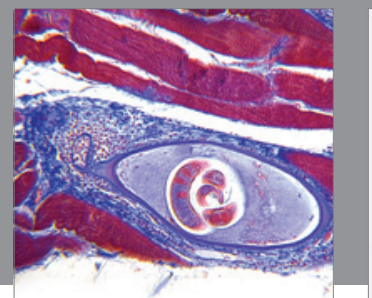

Gastroenterology

Research and Practice
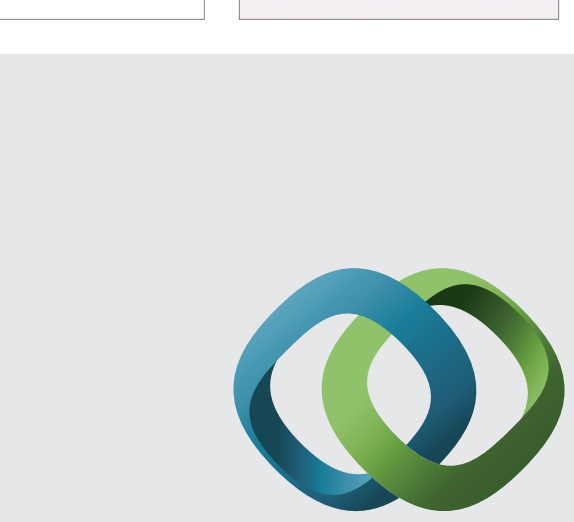

\section{Hindawi}

Submit your manuscripts at

http://www.hindawi.com
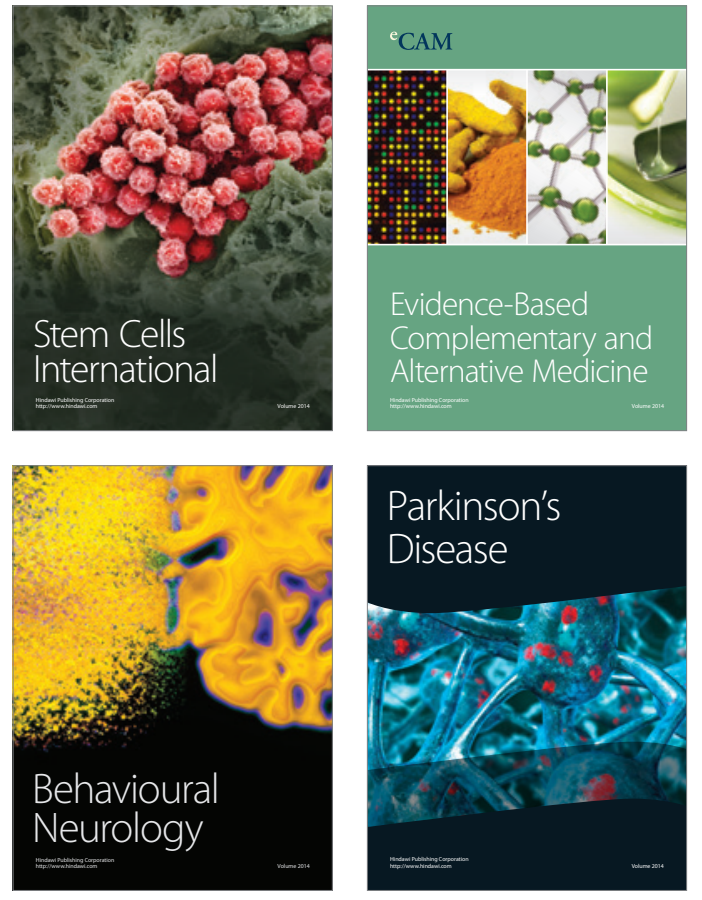
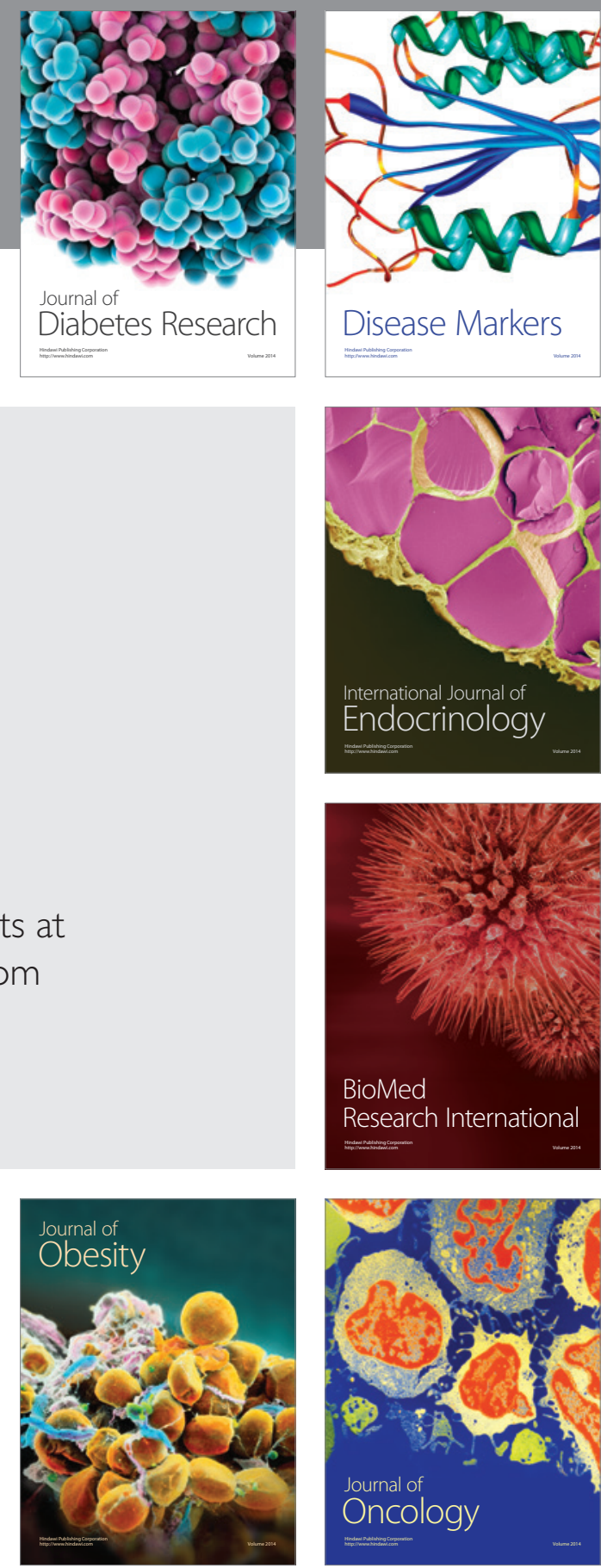

Disease Markers
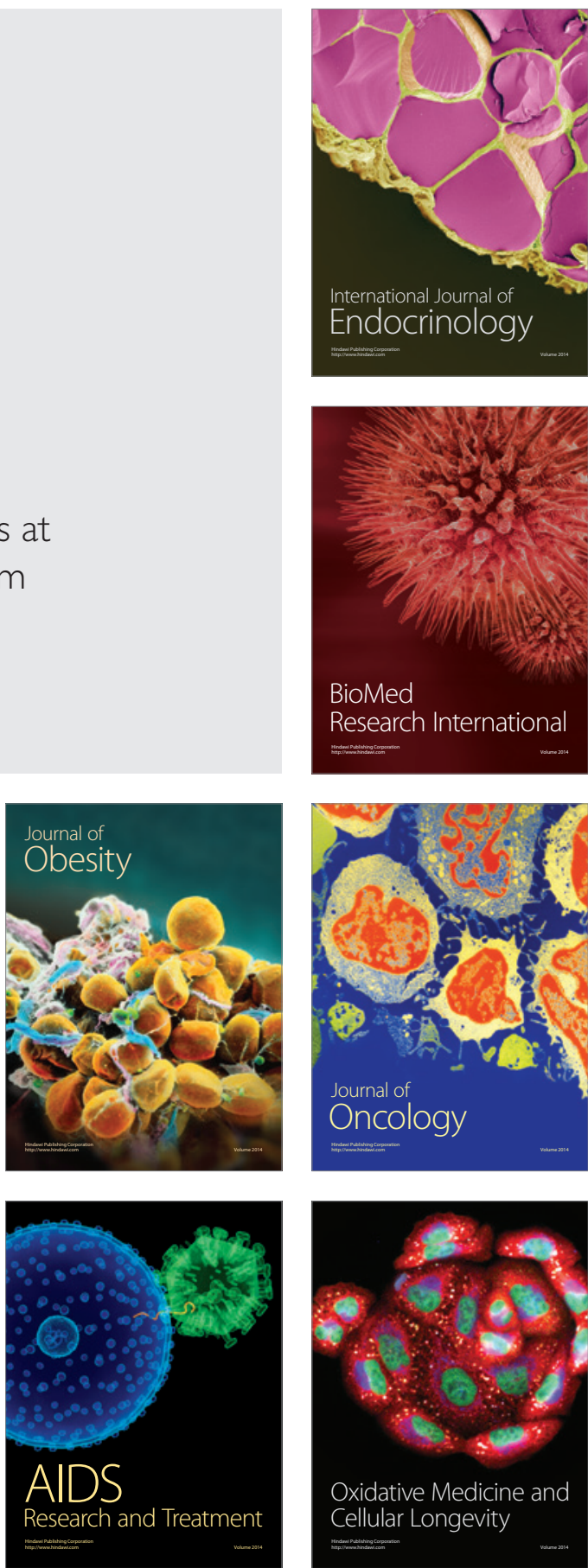